\title{
The effect of prophylactic vitamin C use on COVID-19 infection
}

\author{
(D)Hafize Kizllkaya1, (D) Vedat Gençer ${ }^{2}$ \\ ${ }^{1}$ Yozgat Bozok University, Faculty of Medicine, Department of Internal Medicine, Yozgat, Turkey \\ ${ }^{2}$ Yozgat Bozok University, Faculty of Medicine, Department of Nephrology, Yozgat, Turkey
}

Cite this article as: Kızılkaya H, Gençer V. The effect of prophylactic vitamin C use on COVID-19 infection. J Health Sci Med 2022; 5(1): 13-17.

\begin{abstract}
Aim: In vitamin $\mathrm{C}$ deficiency, the immune system deteriorates and the body becomes more susceptible to infections. Since vitamin $\mathrm{C}$ levels will decrease significantly in infectious conditions due to increased metabolic requirements, the daily need for vitamin $\mathrm{C}$ increases. In our study, it was aimed to investigate the effects of $500 \mathrm{mg}$ and more vitamin C intake on COVID-19 infection during the pandemic process.

Material and Method: A group consisting of 100 participants who received vitamin C supplements at a daily dose of at least $500 \mathrm{mg}$ daily for a minimum of 1-3 months in their diet and a control group of 100 people who did not receive vitamin supplements were included in the study. While determining the amount of Vitamin C intake of the participants; The amount of Vitamin C in oral food supplements or foods containing vitamin C in their diets (orange, tangerine, grapefruit, kiwi, pineapple, strawberry, lemon, red and green peppers, tomatoes, arugula, parsley, greens such as lettuce, fresh rosehip, broccoli, cabbage, spinach) The vitamin level was calculated according to the amount of vegetables (such as vegetables). None of the participants had side effects suggestive of vitamin $\mathrm{C}$ toxicity. Besides the height, weight, gender, age, known illness and other demographic data of all participants; COVID-19 disease status, contact with COVID-19 patients, and whether or not they had a COVID infection after contact were examined. In addition, data on the presence of symptoms, severity and duration of the disease were noted in patients with COVID-19 infection, and both groups were compared statistically in terms of results.

Results: In the group receiving less than $500 \mathrm{mg}$ daily; COVID-19 infection symptoms, respiratory distress, disease severity were found to be higher, and the symptoms were found to be more aggressive. While total contact and high-risk contact at all levels was higher in the group that received more than $500 \mathrm{mg}$ of vitamin C daily, the rate of being COVID was lower compared to the other groups.

Conclusion: One of the most effective precautions to be taken to increase body resistance against COVID-19 is adequate vitamin $\mathrm{C}$ intake. In the study, it has been shown that adequate vitamin $\mathrm{C}$ taken with both food and nutritional supplements reduce the risk of getting COVID-19, reduce the risk of severe respiratory distress on COVID-19, as well as reduce both symptoms and symptom duration.
\end{abstract}

Keywords: COVID-19, prophylactic vitamin C, COVID-19 violence

\section{INTRODUCTION}

Vitamin C (ascorbic acid) is one of the essential watersoluble nutrients. It is synthesized from fructose in plants and glucose in animals. Since it is not synthesized in humans, it must be taken from outside (1). The immune system is a specialized, versatile mechanism developed to protect the body from pathogens. It is divided into congenital immunity and acquired immunity (2). For nearly fifty years, it has been stated that vitamin C has a very important role, especially in the function of immune system cells (3). The recommended daily intake of vitamin C is $110 \mathrm{mg} /$ day for men and $95 \mathrm{mg} /$ day for women (4). However, in a person exposed to infectious agents and under physical stress, this amount may be insufficient. In order to meet the nutritional needs of the general population and especially adults aged 65 and over, $200 \mathrm{mg}$ of supplements per day is recommended. In addition, it recommends $400 \mathrm{mg}$ per day for individuals 50 years+ of age to strengthen the immune system (5). 
To date, 7 corona viruses with respiratory tract involvement have been identified in human beings (HCoVs). Effective in COVID is considered to be betaCoVs (6). Culture, electron microscopy and serological tests are used for diagnosis. There are four types of proteins called spike (S), envelope (E), membrane (M) and nucleocapsid $(\mathrm{N})$ that participate in the structure of the virus. The $S$ protein enables the viral genome to enter the cell by establishing a connection between the cell it will affect and the virus. $\mathrm{E}$ and $\mathrm{M}$ proteins participate in the transmembrane structure. Nucleocapsid $(\mathrm{N})$ is used in the cloning and production of recombinant proteins (7).

There is no treatment for COVID-19 yet. Vitamin C has become a potentially helpful Candidate for COVID-19 treatment due to its antioxidant, anti-inflammatory and immunomodulatory properties. To date, oral vitamin $\mathrm{C}$ has been shown to reduce both the duration and frequency of respiratory infections. In addition, intravenous vitamin $\mathrm{C}$ has been shown to reduce hospital stay, stay in mechanical ventilation and intensive care, and reduce mortality. The benefits of using vitamin $\mathrm{C}$ in COVID-19 have been shown due to the low cost of vitamin $\mathrm{C}$, the high safety profile, and the increased need for vitamin $C$ during inflammation (5). The need for vitamin $\mathrm{C}$ has increased during viral infections such as COVID-19. In these cases, the amount required to keep vitamin $\mathrm{C}$ within normal plasma levels has been determined as 2-3 g/day (8). Studies have shown that low vitamin $C$ is associated with high oxidative stress. Since vitamin $C$ is reduced in cases of pneumonia and sepsis, studies have been conducted showing the effectiveness of vitamin C in these groups (9). Our aim in this study; to investigate the effects of the amount of vitamin $\mathrm{C}$ taken orally on COVID-19 symptoms, duration and severity of symptoms.

\section{MATERIAL AND METHOD}

This study was approved by Yozgat Bozok University Faculty of Medicine Clinical Researches Ethics Committee (Date: 16.12.2020, Decision No: 2017KAEK-189-2020.12_06). All procedures were carried out in accordance with the ethical rules and the principles of the Declaration of Helsinki.

Patients over the age of 18 who applied to Yozgat Bozok University Medical Faculty internal medicine outpatient clinics were included in our study. The diet of the patients was questioned and evaluated according to their prophylactic vitamin $\mathrm{C}$ content during the pandemic process.

When calculating the amount of vitamin $\mathrm{C}$ in the diet of the patients, the foods containing vitamin $\mathrm{C}$ in the food supplement or diet (orange, tangerine, grapefruit, kiwi, pineapple, strawberry, lemon, red and green pepper, tomato, arugula, parsley, lettuce, fresh rosehip, broccoli, cabbage considering the amount of spinach) were included in the study.

Accordingly, the participants were divided into two groups as patients with or without vitamin $\mathrm{C}$ at a daily dose of at least $500 \mathrm{mg}$ (10) between 1-3 months on a regular basis. In addition to the height, weight, gender, age, known disease and other demographic data of all participants, COVID-19 disease status and contact with COVID-19 patients were evaluated.

Accordingly, people in intensive contact with COVID-19 patients wearing a Medical (Surgical) mask;

- if all personal protective equipment (PPE) was used properly considered as risk-free,

- if not wearing gloves and gowns or eye protection considered as low risk,

- if not used medical mask or N95 or medical mask in case of N95 indication considered as medium risk.

The data obtained from the questionnaires containing data on the condition of the same participants after contact with COVID-19, and the disease symptoms of patients with COVID-19, the severity and duration of the disease were noted and statistically compared in terms of both groups (11).

\section{RESULTS}

Of the two hundred participants in the study, $52.5 \%$ $(n=105)$ were female and $47.5 \%(n=95)$ were male. The average age was 44.18 years, average height $168.21 \mathrm{~cm}$, average weight $75.83 \mathrm{~kg}$, and body mass index $26.79 \mathrm{~kg} /$ $\mathrm{cm}^{2}$.

$100(50 \%)$ of were using $500 \mathrm{mg}$ or more prophylactic oral vitamin $\mathrm{C}$ daily. Among all participants, the rate of getting COVID-19 disease was 52.5\%, and the frequency of symptoms in those with COVID was $49.5 \%$.

Any statistically significant difference was found between the groups (receiving $500 \mathrm{mg}$ or more prophylactic oral vitamin C per day $(\mathrm{n}=100)$ and less than $500 \mathrm{mg}(\mathrm{n}=100))$ in terms of age, gender, height, weight, BMI, smoking and alcohol use, and being COVID-19 ( $\mathrm{p}>0.05)$.

When both groups are evaluated in terms of chronic diseases; while there was no significant difference in terms of hypertension, chronic renal failure, chronic heart disease, asthma ( $p>0.05)$; those with chronic obstructive pulmonary disease were more in the vitamin $\mathrm{C}$ group; and the number of patients with diabetes mellitus was higher in the group not receiving vitamin $\mathrm{C}$ supplements $(\mathrm{p}<0.05)$ (Table 1). 
While $46 \%$ of the patient group who received $500 \mathrm{mg}$ and more prophylactic oral vitamin $\mathrm{C}$ per day became COVID, this rate was 59\% in the group receiving less than $500 \mathrm{mg}$ per day. COVID-19 ratio was similar in both groups $(\mathrm{p}=0.066)$. Disease duration, COVID symptoms, respiratory distress, and disease severity were found to be significantly higher in the group receiving less than $500 \mathrm{mg}$ daily $(\mathrm{p}<0.05)$. In the group receiving more than $500 \mathrm{mg}$ of vitamin C per day, $86.9 \%$ of the patients who had COVID-19, and $100 \%$ of the patients in the group receiving less than $500 \mathrm{mg}$ per day showed symptoms. In addition, when the symptomatic ones are evaluated within themselves; while most of the people who take more than $500 \mathrm{mg}$ of vitamin $\mathrm{C}$ per day have mild symptoms; those taking vitamin $\mathrm{C}$ below $500 \mathrm{mg}$ per day were found to have the majority of moderate symptoms. Education level and income level were similar between the groups ( $p>0.05)$ (Table 2).

While total contact at all levels was $74 \%$ and high-risk contact was $42 \%$ in the group receiving more than 500 $\mathrm{mg}$ of vitamin C daily, this rate was found to be $52 \%$ and $28 \%$, respectively in the group receiving vitamin $\mathrm{C}$ below $500 \mathrm{mg}$ per day. In the group that received more than $500 \mathrm{mg}$ of vitamin $\mathrm{C}$ daily, the contact rates were found to be significantly higher than the other group $(\mathrm{p}<0.05)$ (Table 3).

\section{DISCUSSION}

In this study, daily prophylactic oral vitamin $C$ intake of $500 \mathrm{mg}$ and above; although there was more contact with COVID and there was a higher risk of contact, the rate of becoming COVID afterwards was found to be significantly lower than the group with a vitamin C intake of less than $500 \mathrm{mg}$. In addition, it was observed that individuals who took $500 \mathrm{mg}$ and more vitamin $\mathrm{C}$ had COVID, their symptoms were milder and the symptom duration was shorter.

The RNA virus called Coronavirus 2 (SARS-CoV-2) causes COVID-19 disease. Coronaviruses take their name from surface proteins called corona (crown) to bind and penetrate host cells (13). It may be asymptomatic or cause serious complications such as flu symptoms, fever, cough, gastrointestinal system symptoms, shortness of breath, pneumonia, respiratory failure and kidney failure. It also has a 3\% mortality (14).

Vitamin C has many roles such as energy metabolism, collagen synthesis and repair, adrenal steroid, catecholamine production, iron absorption. In addition, it reduces the risk of infection due to its antimicrobial, immunomodulatory and antioxidant properties (15). Vitamin $\mathrm{C}$ protects the mucosal barrier by reducing viral adhesion (16). It has been shown that individuals with
Table 1. Demographic and clinical parameters of groups receiving $500 \mathrm{mg}$ or more daily and less than $500 \mathrm{mg}$ daily oral vitamin C

\begin{tabular}{|c|c|c|c|}
\hline \multirow[b]{2}{*}{ Properties } & \multicolumn{2}{|c|}{ Vitamin C } & \multirow[b]{2}{*}{$\mathbf{P}$} \\
\hline & $\begin{array}{l}\text { Daily } 500 \mathrm{mg} \text { and } \\
\text { more }(\mathrm{n}=100)\end{array}$ & $\begin{array}{l}\text { Daily less than } \\
500 \mathrm{mg}(\mathrm{n}=100)\end{array}$ & \\
\hline Age & $45.37 \pm 15.31$ & $43.00 \pm 16.01$ & 0.286 \\
\hline Gender $(\mathrm{m} / \mathrm{f})$ & $51 / 49$ & $44 / 56$ & 0.322 \\
\hline Height $(\mathrm{cm})$ & $168.68 \pm 8.86$ & $167.74 \pm 8.77$ & 0.452 \\
\hline Weight (kg) & $75.60 \pm 13.82$ & $76.07 \pm 17.51$ & 0.833 \\
\hline $\mathrm{BMI}\left(\mathrm{kg} / \mathrm{cm}^{2}\right)$ & $26.65 \pm 5.14$ & $26.92 \pm 5.43$ & 0.322 \\
\hline Cigarettes (\%) & 29 & 25 & 0.524 \\
\hline Alcohol (\%) & 6 & 4 & 0.516 \\
\hline COVID-19 (\%) & 46 & 59 & 0.066 \\
\hline
\end{tabular}

Table 2. Comparison of the effects of oral prophylactic vitamin C supplementation on COVID-19 infection and comparison of education and income levels

\begin{tabular}{|c|c|c|c|}
\hline \multirow[b]{2}{*}{ COVID-19 Data } & \multicolumn{2}{|c|}{ Vitamin C } & \multirow[b]{2}{*}{$\mathbf{P}$} \\
\hline & $\begin{array}{c}\text { Daily } 500 \\
\text { mg and more } \\
(n=100)\end{array}$ & $\begin{array}{c}\text { Daily less } \\
\text { than } 500 \mathrm{mg} \\
(\mathrm{n}=100)\end{array}$ & \\
\hline Respiratory distress & & & 0.031 \\
\hline No infection & 48 & 44 & \\
\hline $\mathrm{Nasal} \mathrm{O}_{2}$ taken & 8 & 2 & \\
\hline CPAP taken & 1 & 0 & \\
\hline Intubated & 2 & 0 & \\
\hline Disease duration & & & $<0.05$ \\
\hline$<1$ day & 1 & 10 & \\
\hline 1-3 days & 1 & 16 & \\
\hline 3-7 days & 15 & 14 & \\
\hline 7-14 days & 23 & 6 & \\
\hline$>14$ days & 19 & 0 & \\
\hline Disease severity & & & $<0.05$ \\
\hline No Infection & 0 & 1 & \\
\hline Mild & 7 & 34 & \\
\hline Medium & 27 & 11 & \\
\hline Severe & 25 & 0 & \\
\hline Disease symptoms & & & 0.012 \\
\hline None & 0 & 6 & \\
\hline Infected & 59 & 40 & \\
\hline Income level & & & 0.55 \\
\hline Low & 29 & 15 & \\
\hline Medium & 24 & 27 & \\
\hline High & 47 & 58 & \\
\hline Education level & & & 0.60 \\
\hline Primary & 27 & 14 & \\
\hline Secondary & 11 & 19 & \\
\hline College & 53 & 61 & \\
\hline Masters & 9 & 6 & \\
\hline
\end{tabular}

Table 3. Effects of prophylactic oral vitamin $\mathrm{C}$ supplementation on COVID-19 infection

\begin{tabular}{|c|c|c|c|c|c|}
\hline \multirow{2}{*}{$\begin{array}{l}\text { COVID-19 } \\
\text { Vitamin C }\end{array}$} & \multicolumn{4}{|c|}{ Contacted } & \multirow{2}{*}{$\mathbf{P}$} \\
\hline & None & Low & Medium & High & \\
\hline Infected & & & & & $<0.05$ \\
\hline Daily less than $500 \mathrm{mg}$ & 37 & 2 & 1 & 1 & \\
\hline Daily $500 \mathrm{mg}$ and more & 19 & 9 & 5 & 21 & \\
\hline Not infected & & & & & $<0.05$ \\
\hline Daily less than $500 \mathrm{mg}$ & 11 & 7 & 14 & 27 & \\
\hline Daily $500 \mathrm{mg}$ and more & 7 & 3 & 12 & 21 & \\
\hline
\end{tabular}


low dietary intake of vitamin $\mathrm{C}$ have a reduced risk of pneumonia with oral vitamin C supplements (17). In our study, the symptoms of those who took $500 \mathrm{mg}$ or more prophylactic vitamin $\mathrm{C}$ were mild. This suggests that for those who take higher doses of vitamin C, mucosal viral transmission may be prevented, resulting in less viral load and, consequently, COVID-19 symptoms are milder. In addition, the duration of symptoms was found to be significantly lower in the vitamin $\mathrm{C}$ group in our study. It may be due to the antimicrobial, immunomodular effects of vitamin C.

Vitamin $\mathrm{C}$ is very important for immunity. The efficacy of chemokines, cytokines, adhesion molecules, inflammatory mediators and apoptosis inhibitors in the immune system has been demonstrated. While inhibiting the production of IL- 6 and tumor necrosis factor alpha (TNF- $\alpha$ ), GM-CSF may decrease the signal response. Tine vitamin $\mathrm{C}$ helps regulate the proliferation and functioning of $\mathrm{T}$ and $\mathrm{B}$ cells and natural killer (NK) cells and prevents the cytokine storm from progressing. Oxidative stress has a damaging effect on viral respiratory infections. With vitamin C, the response to oxidative stress increases. The role of oxidative stress in the mechanism of COVID-19 has been emphasized (16). Oxidative stress, immunological damage, endothelial and alveolar membrane damage have been reported in the mechanism of COVID. In the pathophysiology of the progression to Covi19 pneumonia and respiratory failure, the excessive response of the immune system involving IL-6 and endothelin-1 (ET-1) is involved (18). Considering these mechanisms, many treatment regimens that can affect different pathways for Covil9 treatment have been tried. Due to its effect on reducing both COVID and non-COVID hyperinflammation, intravenous vitamin $\mathrm{C}$ administration has also taken its place among these regimens. Due to its antioxidant, anti-inflammatory, antithrombotic and immunomodulatory aspects, high amounts of intravenous vitamin $\mathrm{C}$ were administered to normalize plasma levels, especially in patients with critically ill sepsis, and it has been shown to reduce mortality (9).

Again in clinical studies; In patients diagnosed with acute respiratory distress syndrome (ARDS) and sepsis, it has been shown that there is a variable degree of effectiveness in cytokine storm with the administration of high doses of intravenous vitamin C. Therefore, it was thought that it could be added to the treatment of ARDS and the treatment of multiorgan dysfunction associated with COVID (16). In our study, respiratory distress was found to be higher in the group that did not take sufficient vitamin $\mathrm{C}$, and the rate of patients who received CPAP and was intubated was higher in this group.
Previous publications on intravenous vitamin C included the results of the application after the diagnosis of COVID-19. Given that vitamin C has substantial evidence on immunity and is also cheap and safe, it was thought that the use of oral prophylactic could be beneficial and the (very) high-dose regimen could be beneficial in severe cases of Covi19, but clinical studies were expected to provide more conclusive evidence (18).

Our study has some limitations. First, the small number of patients, and secondly, the participants were not questioned in terms of other vitamins and minerals that affect immunity. Although the COVID-19 contact of the patients is questioned, the information given about the contact of the patients may not give a definite result due to the asymptomatic COVID-19 cases.

In addition, there might be individuals who stated that they did not have COVID-19 because they were asymptomatic, and those who are misdiagnoses caused by false negative results of the PCR test.

\section{CONCLUSION}

In our study, the effects of prophylactic oral use of vitamin $\mathrm{C}$ on COVID were investigated. We need to take measures to strengthen the immune system against COVID infection, which has a wide range of symptoms. One of these measures is adequate vitamin $\mathrm{C}$ intake. Adequate vitamin $\mathrm{C}$ supplements taken with foods and nutritional supplements; has been shown in our study that reduces the risk of getting COVID after contact, reduces severe respiratory distress in those with COVID, and also reduces both symptoms and symptom duration. Previously, publications on intravenous vitamin $\mathrm{C}$ included the results of the application after the diagnosis of COVID. Considering that vitamin C has substantial evidence on immunity and is also cheap and safe, oral prophylactic use may be beneficial.

\section{ETHICAL DECLARATIONS}

Ethics Committee Approval: This study was approved by Yozgat Bozok University Faculty of Medicine Clinical Researches Ethics Committee (Date: 16.12.2020, Decision No: 2017-KAEK-189-2020.12_06).

Informed Consent: All patients signed the free and informed consent form.

Referee Evaluation Process: Externally peer-reviewed.

Conflict of Interest Statement: The authors have no conflicts of interest to declare.

Financial Disclosure: The authors declared that this study has received no financial support. 
Author Contributions: All of the authors declare that they have all participated in the design, execution, and analysis of the paper, and that they have approved the final version.

\section{REFERENCES}

1. Drouin G, JR Godin, B Pagé, The genetics of vitamin C loss in vertebrates. Curr Genomics 2011; 12: 371-8.

2. Carr AC, Maggini S. Vitamin C and immune function. Nutrients 2017; 9: 1211.

3. Maggini S, Wintergerst ES, Beveridge S, Hornig DH. Selected vitamins and trace elements support immune function by strengthening epithelial barriers and cellular and humoral immune responses. Br J Nutr 2007; 98: 29-35.

4. German Nutrition Society (DGE). New reference values for vitamin C intake. Ann Nutr Metab 2015; 67: 13-20.

5. Holford P, Carr AC, Jovic TH, et al. Vitamin C-an adjunctive therapy for respiratory infection, sepsis and COVID-19. Nutrients 2020; 12: 3760 .

6. Naserghandi A, Allameh SF, Saffarpour R. All about COVID-19 in brief. New Microbes New Infect 2020; 35: 100678.

7. Hemilä H. Vitamin C and infections. Nutrients 2017; 9: 339.

8. Hume R, Weyers E. Changes in leucocyte ascorbic acid during the common cold. Scott Med J 1973; 18: 3-7.

9. Carr AC, Rowe $\mathrm{S}$. The emerging role of vitamin $\mathrm{C}$ in the prevention and treatment of COVID-19. Nutrients 2020; 12: 3286.

10. Johnston CS, Cox SK. Plasma-saturating intakes of vitamin C confer maximal antioxidant protection to plasma. J Am Coll Nutr 2001; 20: 623-7.

11. Ministry of Health, Press Release " Fahrettin Koca announced the number for the first time: 29,865 healthcare workers are infected..... Medimagazin 2020; Available from: https://www. medimagazin.com.tr/guncel/genel/tr-fahrettin-koca-ilk-kezsayi-verdi-29-bin865-saglik-calisani-enfekte-11-681-91089.html.

12. Stoecklin SB, Rolland P, Silue Y, et al., First cases of coronavirus disease 2019 (COVID-19) in France: surveillance, investigations and control measures, January 2020. Euro Surveill 2020; 25: 2000094

13.Lu R, Zhao X, Li J, et al., Genomic characterisation and epidemiology of 2019 novel coronavirus: implications for virus origins and receptor binding. Lancet 2020; 395: 565-74.

14. Erbay A. Long COVID: a new definition. Bozok Tip Derg 2020; 10: 111-4.

15. Mousavi S, Bereswil S, Heimesaat MM. Immunomodulatory and antimicrobial effects of vitamin C. Eur J Microbiol Immunol (Bp) 2019; 9: 73-9.

16. Liu F, Zhu Y, Zhang J, Li Y, Peng Z. Intravenous high-dose vitamin $\mathrm{C}$ for the treatment of severe COVID-19: study protocol for a multicentre randomised controlled trial. BMJ Open 2020; 10: 039519.

17. Hemilä H, Louhiala P. Vitamin C for preventing and treating pneumonia. Cochrane Database Syst Rev 2013; 8: 005532.

18. Feyaerts AF, Luyten W. Vitamin C as prophylaxis and adjunctive medical treatment for COVID-19? Nutrition 2020; 79: 110948. 